\title{
SISTEMA PENAL E VIOLÊNCIA DE GÊNERO: análise sociojurídica da Lei 11.340/06
}

\section{Rodrigo Ghiringhelli de Azevedo*}

\begin{abstract}
O presente artigo parte da reflexão acerca do papel da sociologia jurídica na compreensão do funcionamento da atividade legislativa, para analisar a racionalidade e os efeitos prováveis da entrada em vigor da Lei no 11.340/06 (Lei Maria da Penha). Concluise que, ao invés de avançar e desenvolver mecanismos alternativos para a administração de conflitos, possivelmente mais eficazes para alcançar o objetivo de redução da violência, mais uma vez recorreuse ao mito da tutela penal, neste caso ela própria uma manifestação da mesma cultura que se pretende combater.
\end{abstract}

Palavras-chave: sociologia jurídica, violência de gênero, Lei $\mathrm{n}^{\circ}$ 11.340/06.

\section{Introdução}

Analisando aspectos da política criminal nas sociedades pósindustriais contemporâneas, o criminólogo espanhol Jesus-María Silva Sánchez constata a existência de uma tendência dominante na grande maioria dos países no sentido da introdução de novos tipos penais, assim como um agravamento das penas para os já existentes, fato que o leva a caracterizar o momento atual como de expansão do direito penal (Silva Sánchez, 2002, p. 21).

Silva Sánchez reconhece que a questão é complexa, e, na linha de David Garland (2001), procura relacionar o fenômeno

\footnotetext{
* Sociólogo, professor e pesquisador do Programa de Pós-Graduação em Ciências Criminais e em Ciências Sociais da Pontifícia Universidade Católica do Rio Grande do Sul (PUCRS).E-mail:rodrigo.azevedo@pucrs.br
}

Artigo recebido em 21 out. 2007 e aprovado em 27 abr. 2008. 
com causas mais profundas e múltiplas, que fundam suas raízes no modelo social que vem se configurando no decorrer das últimas décadas. Segundo ele, há que se reconhecer a existência de uma verdadeira demanda social por mais proteção ante o incremento da criminalidade, canalizada de modo mais ou menos irracional como demanda de punição.

Buscando formular hipóteses explicativas para o fenômeno, Silva Sánchez vai arrolar alguns fatores que justificariam a cristalização deste consenso. Um deles seria o surgimento de novos bens jurídicos considerados socialmente relevantes para a obtenção da tutela penal. Tal situação seria verificável tanto pelo surgimento de novas esferas de ação potencialmente delitivas, como o ciberespaço, como pelo reconhecimento da relevância de determinadas condutas delitivas antes consideradas de menor importância, como a violência no ambiente doméstico, e ainda a deterioração de realidades tradicionalmente abundantes, levando à criminalização das condutas lesivas ao meio ambiente.

Outro fator apontado por Silva Sánchez para a expansão do Direito Penal é a mudança de posição de boa parte dos criminólogos de esquerda, que se tornam os novos "gestores atípicos da moral". Uma vez que se passa a visualizar os sujeitos pertencentes aos estratos inferiores da sociedade como titulares de bens jurídicos individuais ou difusos, como vítimas potenciais mais do que como autores potenciais de delitos, a esquerda passa a assumir as demandas de maior proteção que surgem de tais setores. As associações ecológicas, feministas, de consumidores, de vizinhos, pacifistas, antidiscriminatórias e de defesa dos direitos humanos passam a encabeçar a tendência de progressiva ampliação do Direito Penal no sentido da crescente proteção de seus interesses específicos. ${ }^{1}$

É nesse contexto que deve ser compreendida a criação da Lei $\mathrm{n}^{\mathrm{o}}$ 11.340/06 (Lei Maria da Penha) no Brasil, buscando dar conta de um fenômeno que vitimiza cotidianamente um grande número de mulheres em todo o país. 


\section{Como lembra Bárbara Soares,}

com a criminalização da violência que acontece no espaço doméstico, redefinem-se os sentidos da individualidade, dos direitos, das responsabilidades e as fronteiras entre o mundo público e o mundo privado. Se estas fronteiras nunca foram estáveis e definitivas na história do Ocidente, é certo, também, que o espaço público nunca esteve tão confundido com a intimidade e com a vida em família, como nesse início de século, em nome de expectativas igualitárias e do amplo acesso aos direitos civis - como tem acontecido sobretudo na América do Norte e em alguns países da Europa. (Soares, 1999, p. 32).

Bárbara Soares destaca que esse processo pode ser lido de formas diferentes. De um lado, como sintoma de aumento do controle social e das formas de dominação, regulação e racionalização da vida coletiva, as quais se sofisticam e se tornam crescentemente pervasivas. A sociedade estaria se tornando mais e mais regulatória e opressiva, já que nem a família, nem as relações íntimas estariam a salvo do controle externo e das investidas da lei. O mundo laicizado e desencantado estaria submetido ao imperativo da razão técnica e ao jugo dos especialistas, que passam a legislar sobre esferas antes reservadas à família e às relações íntimas. A vida privada se institucionaliza e é devorada pela lógica do processo burocratizante que prevalece na vida pública. O refúgio do afeto e do valor é invadido pelos guardiões da nova racionalidade política e pelos profissionais da subjetividade, que passam a administrar o amor, a sexualidade, as emoções e as tradições familiares, imiscuindo-se no terreno das crenças, dos hábitos, das relações interpessoais.

Por outro lado, Bárbara Soares sustenta que esse processo pode ser interpretado de outra maneira: o processo de redefinição de direitos, baseado em uma releitura desnaturalizante da vida social, encabeçada primordialmente pelas feministas, indicaria, também, uma expansão da democracia e uma extensão do sentido da individualidade. O lar, o casal e a família deixam de funcionar como 
mônadas impenetráveis, como núcleos decisórios, auto-referidos e possuidores de direitos próprios, para se desmembrarem em novas unidades socialmente significativas, competindo legitimamente e em igualdade de condições pelo acesso aos direitos civis.

$\mathrm{Na}$ direção inversa à que a primeira leitura sugere, o mundo privado estaria, nesse caso, se arremessando sobre a esfera pública, impondo suas temáticas e contaminando-o com suas feridas, suas paixões, seus desejos, sua irracionalidade e selvageria. Em vez do simples controle dos excessos, dos afetos, dos desvios e diferenças, o movimento contra a violência estaria transferindo para o domínio público as turbulências, perplexidades e incertezas vividas na privacidade. Estaria desestabilizando e redefinindo o foco das percepções sobre dominação, controle e poder. Por romper as velhas estruturas do patriarcalismo e desnaturalizar os dispositivos que asseguram o livre exercício da violência familiar, estaria, pragmaticamente, produzindo condições de ampliação da democracia, a despeito de seus efeitos colaterais.

Mesmo considerando os excessos e os novos problemas que advêm da intervenção externa sobre a família, numa perspectiva emancipatória a segunda leitura parece plausível, uma vez que, em última instância, é contra a limitação da cidadania plena e a expansão do acesso à igualdade de direitos que se organiza o movimento contra a violência de gênero/doméstica/conjugal. Estaria assim contemplada a racionalidade ética de uma intervenção institucionalizada neste âmbito.

Resta, no entanto, indagar acerca da racionalidade pragmática ou teleológica das intervenções que se pretende fazer sobre a realidade social por meio de reformas legais, especialmente no âmbito do direito penal. Uma lei é irracional, neste âmbito, se fracassa em seu propósito de influenciar o comportamento humano, por motivos subjetivos ou objetivos, ou se produz efeitos não previstos e/ou não 
desejados, o que somente pode ser observado por meio de técnicas de implementação e monitoramento.

\section{O controle penal nos estudos sociocriminológicos}

No âmbito dos estudos criminológicos, a partir da década de 60 do século XX abriu-se uma nova perspectiva de análise da criminalidade e do controle social com vista a colocar em relevo o debate sobre como se mantém a autoridade em sociedades permeadas por conflitos sociais. Os novos sociólogos do conflito inverteram a premissa de Parsons de que o controle social era uma reação à transgressão, afirmando que o controle leva à transgressão. É o caso de Howard Becker, que em Outsiders (1991) afirmou que as instituições de controle criam indivíduos à margem, sejam eles criminosos, doentes mentais ou minorias religiosas e raciais, que servem de bodes expiatórios sociais e também como última fronteira da "sociedade respeitável". O enfoque microssociológico do interacionismo simbólico coloca em destaque o caráter negociado e não mecanicamente imposto da ordem social, em um contexto no qual os atores sociais fazem uma permanente reinterpretação das regras, em um processo dinâmico.

Ralf Dahrendorf (1994), um dos representantes da Sociologia do Conflito, sustenta a normalidade das mudanças e dos conflitos sociais, e a coesão social não é derivada do consenso sobre valores comuns, e sim da coação exercida pelos mecanismos de controle. Seguindo as lições de Max Weber, Dahendorf concebe a sociedade como um emaranhado de grupos de interesse. A desigualdade na distribuição do poder e da autoridade gera dois tipos de grupos: os que detêm o poder e a autoridade e os que estão submetidos ao controle dos primeiros. Estes grupos se encontram permanentemente em conflito e estão sempre empenhados em conseguir transformar as normas e valores para conseguir que os sistemas de estratificação 
social e de avaliação moral se modifiquem. Ao promover a adequação da estrutura social às condições sociais emergentes, com a mediação das instituições democráticas, os conflitos contribuem para um desenvolvimento social mais justo e efetivo da ordem social.

Com a emergência da Sociologia da Conflitualidade e do paradigma da reação social, a pesquisa sociológica começa a afastar-se da preocupação com o comportamento desviante considerado em si mesmo, e volta-se, orientada também pela crítica marxista do estrutural-funcionalismo e pela preocupação weberiana com o poder e a dominação em sociedades nas quais se expressa uma multiplicidade de interesses conflitantes, para a atividade de controle social exercida pelos aparelhos estatais de justiça e pelos serviços sociais do Estado providência. Nessa perspectiva, o fundamento e o exercício do controle social passam a vincularse mais diretamente ao problema da dominação cultural, política e econômica de determinados grupos sobre os demais. A reação social ao desvio evolui, nas sociedades modernas, em direção a modos de controle mais formais e mais institucionalizados (o direito e as instituições judiciárias estatais), mas também na direção de técnicas baseadas mais na persuasão do que na coerção, através dos meios de comunicação de massa.

A emergência de um controle social do tipo jurídico expressa a autonomização do direito em relação à esfera cultural (principalmente em relação à religião), vindo suplementar os costumes e tradições na orientação das condutas sociais, e desempenhando um papel indispensável na interpretação das normas sociais e na resolução pacífica dos conflitos em sociedades marcadas pelo pluralismo cultural.

As pesquisas empíricas da sociologia do direito, a partir dos anos 60 , orientam-se pelo estudo da complexidade que está por trás da relação entre normatividade estatal e orientação dos comportamentos individuais, através dos diversos níveis de realização do sistema de 
controle penal. O resultado é a imposição de uma noção relativista e pluralista a respeito das normas jurídicas, pelo reconhecimento de que sua autoridade nem sempre estaria baseada na legitimidade do consenso. A precisão e a generalidade das regras de direito, preocupação da dogmática jurídica, revelam-se mais formais do que reais, sendo permanentemente submetidas a uma reinterpretação dinâmica e variável pelos responsáveis pela sua aplicação e objeto de uma permanente negociação.

Tanto os processos de criação quanto de aplicação das normas jurídicas em geral, e das normas penais em particular, respondem a certas orientações que não coincidem sempre com aquelas que as normas parecem enunciar. Além disso, é preciso levar em conta as conseqüências imprevistas da entrada em vigor de novas normas jurídicas, que muitas vezes não correspondem ao objetivo do legislador ao aprová-la. Assim, os estudos não-dogmáticos e metanormativos centrados na origem, no conteúdo e na incidência das normas jurídico-penais sobre a sociedade passaram a constituir o campo empírico de reflexão da sociologia do controle penal.

Mas, como lembra Dominguez Figueirido,

La explicación que nos ofrece la sociología del conflicto sobre la relación entre conflicto social y orden normativo adolece de una cierta simplificación mecanicista. Salvo una genérica referencia a la instrumentalización del derecho por parte de los poderosos, poco se explica sobre la función del sistema jurídico en el sistema social y menos sobre la dinámica de desarrollo de los procesos de criminalización primaria. El legislativo se imagina, tras la lectura de los conflictualistas, como una simple correa de transmisión de los deseos del poder del más fuerte. Y una explicación de este tipo resulta, si cabe, más insuficiente en el contexto del Estado de Bienestar, en el cual el sistema jurídico asume complejas tareas de integración social a través de la coordinación de los intereses de los diversos sectores sociales. (Domínguez Figueirido, 2003, p. 252).

De qualquer forma, a superação do paradigma estático do estrutural-funcionalismo, promovida tanto pelas teorias do conflito 
quanto pelo labeling approach, abriu a possibilidade de uma visão e abordagem dinâmica e contínua do sistema penal, onde é possível individualizar segmentos que vão desde o legislador até os órgãos judiciais e prisionais. Nessa perspectiva, os processos de criminalização promovidos pelo sistema penal se integram na mecânica de um sistema mais amplo de controle social e de seleção das condutas consideradas desviantes.

Mesmo em uma perspectiva sistêmica, como a sustentada por Niklas Luhmann, é possível reconhecer a relevância da preocupação com as dificuldades de comunicação entre o subsistema jurídico e o sistema social, colocando em destaque o problema da impossibilidade de realizar os fins pretendidos pelo legislador de forma automática.

Partindo da noção de que os sistemas e subsistemas sociais são sistemas diferenciados de produção de sentido que visam à redução da complexidade, Luhmann vê o direito como aquela estrutura de um sistema social (subsistema) que tem a função de generalizar as expectativas normativas de comportamento, e com isto garantir a coesão social. É um subsistema que coordena em um nível altamente generalizado e abstrato todos os mecanismos de integração e de controle social. A partir dessa definição, Luhmann vai desenvolver suas investigações sobre as relações entre direito e sociedade a partir de três problemas distintos: o do condicionamento que a sociedade exerce sobre o direito; o do condicionamento que o direito exerce sobre a sociedade; e o reflexivo, da relação entre o estudo do direito e o estudo da sociedade (Treves, 1988, p. 215).

Para Luhmann, o crescimento da complexidade social é a causa de uma transformação das estruturas jurídicas, a fim de que possam exercer sua função de redução da complexidade. Essa transformação ocorre, como mostrou Weber, através do processo de positivação do direito, que desvincula o sistema jurídico de sua tradicional vinculação com o sagrado, substituído pela decisão 
obtida por procedimentos pré-estabelecidos. Dessa forma, a eficácia do sistema de direito positivo depende não tanto da adequação de um conteúdo das normas jurídicas às exigências concretas dos particulares quanto da adequação dos modos de produção dessas normas às exigências de racionalidade e de controle que o nível de complexidade alcançado pelo sistema social e pelo seu entorno requerem em cada momento. ${ }^{2} \mathrm{Um}$ sistema jurídico que funcione adequadamente obtém a sua legitimidade na medida em que é capaz de produzir uma prontidão generalizada para a aceitação de suas decisões, ainda indeterminadas quanto ao seu conteúdo concreto, graças a um procedimento judicial que imuniza a decisão final contra as decepções inevitáveis.

Essa capacidade é garantida, a partir do século XIX, pela separação estrita de dois subsistemas, legislação e jurisprudência, acoplados estruturalmente, como periferia (legislação) e centro (juízes e tribunais) do sistema jurídico. Essa separação permite a canalização diferencial de influências (irritações) externas, e a sua dissolução levaria ao colapso do sistema jurídico e da própria diferenciação entre política e economia. Segundo Luhmann, essa diferenciação

fornece, na sua ação conjunta com outras distinções, sobretudo nas distinções entre codificação binária e programação, igualmente na diferença entre direito e não-direito, por um lado, e normas jurídicopositivas, de outro lado, o pressuposto para que o próprio sistema jurídico se possa diferenciar do seu mundo circundante e para que ele possa, enquanto sistema operativamente fechado, reproduzir suas próprias operações através da rede de operações próprias. (Luhmann, 1990, p. 155).

Embora a maioria das descrições teóricas da distinção entre legislação e jurisprudência partam de um modelo hierárquico, segundo o qual a legislação tem precedência sobre a jurisprudência, de fato essa hierarquia não subsiste, se considerarmos o processo legislativo e o processo jurisdicional como subsistemas autopoiéticos 
fechados. Por um lado, esse fechamento garante que, no caso de um conflito entre a decisão do legislador e a decisão judicial, é o próprio centro do sistema jurídico, isto é, o tribunal, que decide se estamos ou não diante de um conflito. Por outro lado, o processo de constitucionalização do direito positivo e a criação de Cortes Constitucionais reforçam a circularidade auto-referencial do sistema jurídico como fonte última das decisões judiciais. A única coação legal realmente efetiva para o centro do sistema jurídico é a obrigatoriedade da prestação jurisdicional.

No modelo teórico de Luhmann, a legislação deixa de ser compreendida como instância hierarquicamente superior à administração da justiça, passando a ser reconhecida como um órgão periférico, que garante o acoplamento estrutural entre o sistema jurídico e o sistema político. Sua função é acomodar a irritação constante do sistema jurídico pelo sistema político, através de regras genericamente válidas, servindo na prática da administração da justiça apenas para excluir excessos nas decisões de casos individuais. Somente o próprio centro do sistema pode ser concebido hierarquicamente, através das várias instâncias que ligam os juízes singulares aos tribunais.

Quanto ao problema da reflexividade do direito e da sociedade, Luhmann considera que cabe à chamada dogmática jurídica, imersa no sistema jurídico, receber e elaborar as informações que entram no sistema (input - legislação nova, demandas judiciais), com uma orientação no passado para as normas e decisões já estabelecidas. A Sociologia do Direito teria como objeto o output dos sistemas normativos, isto é, os efeitos que esses sistemas produzem no meio, com uma orientação para o futuro, para os problemas de engenharia social.

$\mathrm{Na}$ perspectiva da Criminologia Crítica, sustentada, entre outros, por Alessandro Baratta (1999), não existe uma diferença ontológica entre um ato humano que é qualificado como delito e 
outro que não recebe esta qualificação. Para responder à pergunta de por que alguns atos são tipificados como crimes e outros não, é preciso investigar as funções sociais que cumpre o processo de etiquetamento de certas condutas como criminosas. Segundo esta perspectiva, o direito é ao mesmo tempo um mecanismo que permite gerar consenso em um nível ideológico e que estabelece as regras que o garantem. Como conseqüência, os aparatos ideológicos da sociedade e o aparato repressivo do Estado têm como finalidade última a proteção do sistema produtivo, e a delinqüência não expressa senão as contradições desse sistema.

Mas, como assinala Larrauri (1991), o viés marxista desta interpretação levou ao exagero determinista de compreender as relações sociais, jurídicas e culturais como funcionais ao sistema econômico capitalista, reconduzindo sempre a análise sobre o direito penal à necessidade de defender e reproduzir o sistema econômico.

Nos anos 80, alguns autores vinculados à Criminologia Crítica, como Jock Young (Lea; Young, 2001), propuseram uma releitura parcial da relação entre a atividade estatal e a função do sistema jurídico-penal, sem deixar de lado a importância da atividade dos órgãos de controle social. Por um lado, se reconhece que a intervenção estatal não responde ao objetivo exclusivo de controle social. Por outro lado, se questiona que o controle social sirva sempre, em última instância, aos interesses do Estado ou dos grupos economicamente dominantes.

De fato, as pesquisas empíricas sobre a atividade das agências de controle desenvolvidas pelas ciências sociais desde os anos 60 demonstravam que, mesmo quando estavam submetidas a uma única orientação política, sua atividade era mediada, tanto em suas relações externas como em suas dinâmicas internas, por múltiplas lógicas, conflitos e interesses que dependiam ou se relacionavam com uma pluralidade de atores políticos e sociais e com diversas dinâmicas institucionais. Daí decorre a idéia de que seria possível utilizar o 
direito penal tanto para perseguir infrações aos direitos humanos quanto para defender os interesses das classes sociais mais débeis, fazendo com que a partir dos anos 80 os movimentos progressistas (feministas, ecologistas, antidiscriminatórios) passassem a adotar estrategicamente o recurso ao direito penal, defendendo seu uso simbólico em determinados casos. Se atualiza assim o debate entre os que pretendem reformar o direito penal e os que rechaçam a sua utilização.

No entanto, propor uma reforma das instituições penais a favor dos mais débeis ou um uso simbólico do direito penal sem reconhecer exatamente como se produz a composição de interesses legislativos ou como se desenvolve a comunicação entre o sistema social e o subsistema jurídico acaba por ser absolutamente ineficaz na perspectiva de obter resultados pragmáticos relevantes. É nesse espaço que se evidencia a contribuição teórica e empírica procedente dos estudos sociojurídicos, e, mais concretamente, de uma Sociologia Jurídico-Penal.

\section{A Lei $\mathbf{n}^{0}$ 11.340/06: novas ou velhas (i)racionalidades?}

Dominguez Figueirido (2003, p. 264), seguindo o modelo teórico apresentado por Manuel Atienza, propõe a análise do processo legislativo com base no reconhecimento da existência de uma série de interações que têm lugar entre elementos distintos e que dão lugar a diversos níveis ou âmbitos de racionalidade. Entre os âmbitos de racionalidade legislativa estão a comunicativa ou lingüística (capacidade do emissor da norma transmitir com fluidez a mensagem ao receptor); a jurídico-formal (inserção harmoniosa da nova lei no sistema jurídico); a ética (sustentabilidade ética dos valores orientadores das condutas prescritas e dos fins buscados pela lei); e a pragmática ou teleológica (adequação da conduta dos 
destinatários ao prescrito na lei e capacidade de alcançar os fins sociais perseguidos).

A elaboração da Lei ${ }^{\circ}$ 11.340/06 parte, em grande medida, de uma perspectiva crítica dos resultados obtidos pela criação dos Juizados Especiais Criminais (JECrim) para o equacionamento da violência de gênero. Os problemas normativos e as dificuldades de implantação de um novo modelo para lidar com conflitos de gênero levaram diversos setores do campo jurídico e do movimento de mulheres a adotar um discurso de confrontação e crítica aos Juizados, especialmente direcionado contra a chamada banalização da violência que por via deles estaria ocorrendo, explicitada na prática corriqueira da aplicação de uma medida alternativa correspondente ao pagamento de uma cesta básica pelo acusado, ao invés de investir na mediação e na aplicação de medida mais adequada para o equacionamento do problema sem o recurso à punição.

É o que se verifica, por exemplo, na manifestação da desembargadora Maria Berenice Dias, em obra publicada sobre a Lei $\mathrm{n}^{\circ} 11.340 / 06$ :

A ênfase em afastar a incidência da Lei dos Juizados Especiais nada mais significa do que reação à maneira absolutamente inadequada com que a Justiça cuidava da violência doméstica. A partir do momento em que a lesão corporal leve foi considerada de pequeno potencial ofensivo, surgindo a possibilidade de os conflitos serem solucionados de forma consensual, praticamente deixou de ser punida a violência intrafamiliar. O excesso de serviço levava o juiz a forçar desistências impondo acordos. O seu interesse, como forma de reduzir o volume de demandas, era não deixar que o processo se instalasse. A título de pena restritiva de direito popularizou-se de tal modo a imposição de pagamento de cestas básicas, que o seu efeito punitivo foi inócuo. A vítima sentiu-se ultrajada por sua integridade física ter tão pouca valia, enquanto o agressor adquiriu a consciência de que era "barato bater na mulher". (Dias, 2007, p. 8). 
Nas pesquisas realizadas sobre o funcionamento dos JECrim, não há, no entanto, um consenso sobre o significado de sua implantação para o equacionamento judicial da violência de gênero. Alguns perceberam os JECrim como benéficos à luta das mulheres por dar visibilidade ao problema da violência de gênero, que antes não chegava ao âmbito judicial em virtude da obrigatoriedade do inquérito policial, que acabava não sendo realizado. Outros entenderam que os Juizados ampliaram a rede punitiva estatal, judicializando condutas que antes não chegavam até o judiciário, mas em muito pouco contribuíram para a diminuição do problema da violência conjugal, pela impunidade decorrente da banalização da alternativa da cesta básica.

Contrariando os estudos que concluíram que a Lei 9.099/95 estaria desfavorecendo as mulheres no acesso à Justiça, a pesquisa realizada por Wânia Pasinato (2004) nas Delegacias de Defesa da Mulher do Estado de São Paulo, no período de 1996 a 1999, revelou um aumento expressivo no número de registros policiais de lesões corporais e ameaças, permitindo concluir que Delegacias da Mulher e Juizados Especiais Criminais representaram importantes espaços de referência para as mulheres em situação de violência.

Para Wânia Pasinato, a decisão de recorrer à polícia e a capacidade legal de intervenção no processo judicial, conquistada pelas vítimas sob a nova legislação, revelaram um modo de exercício de poder pelas mulheres, em um modelo alternativo à justiça tradicional que poderia responder às expectativas das mulheres vítimas de violência e explicitar outro tipo de vínculo entre gênero, conflito e Justiça. Wânia trata a possibilidade de manutenção ou retirada da representação pela vítima, viabilizada pela Lei 9.099/95, como um mecanismo de empoderamento das mulheres, pois estas deixariam de ser vítimas passivas para atuarem de forma ativa, reagindo à situação de violência que enfrentam. A capacidade de dispor da representação revelaria formas através das quais as mulheres 
podem exercer poder na relação com os companheiros. Entretanto, a autora chama a atenção para o fato de que o problema não está na possibilidade da vítima se manifestar, retirando a representação, mas na ausência de mecanismos que permitam que ela seja informada de seus direitos e das conseqüências de sua renúncia à representação.

Em um movimento capitaneado pela Secretaria Nacional dos Direitos da Mulher, que se pautou pela tentativa de elaboração normativa por meio da participação direta de mulheres em vários Estados, deixou-se de lado o que há uma década era visto como um novo paradigma, aberto à mediação e à busca do consenso, e verificou-se a adesão à tese da utilização do direito penal para a proteção de interesses legítimos de redução da violência.

Em relação às lesões corporais leves, a Lei ${ }^{0}$ 11.340/06 instituiu um aumento da pena máxima em abstrato, se a lesão for praticada contra ascendente, descendente, irmão, cônjuge ou companheiro, ou com quem conviva ou tenha convivido, ou, ainda, prevalecendo-se o agente das relações domésticas, de coabitação ou de hospitalidade, que passou a ser punido com três meses a três anos de detenção. Com essa medida, retirou dos JECrim a competência para o processamento deste delito, e previu a criação de Juizados de Violência Doméstica e Familiar contra a Mulher.

Optou-se ainda por prever expressamente, no art. 41, que aos crimes praticados com violência doméstica e familiar contra a mulher, independentemente da pena prevista, não se aplica a Lei ${ }^{\circ}$ 9.099/95. Agora, caso o juiz entenda necessário o comparecimento do agressor em programa de recuperação e reeducação, a medida é tomada de forma impositiva, e não mais como parte de uma dinâmica de mediação, ou mesmo de transação penal.

A exclusão do rito da Lei $n^{0} 9.099 / 95$, expressa no art. 41 da Lei $\mathrm{n}^{\mathrm{o}} 11.340 / 06$, para o processamento de casos de violência doméstica, acaba com a possibilidade de conciliação, que se 
constituía em uma oportunidade das partes discutirem o conflito e serem informadas sobre seus direitos e as conseqüências de seus atos. Além disso, reenvia estes delitos para a Polícia Civil, pois agora dependem novamente da produção do inquérito policial. Embora a lei tenha sido bastante minuciosa ao orientar a atividade policial, são conhecidas de todos as dificuldades existentes, tanto estruturais quanto culturais, para que estes delitos venham a receber por parte da Polícia o tratamento adequado, o que certamente vai implicar uma redução do acesso ao Poder Judiciário.

Incluindo a prisão preventiva como medida protetiva de urgência cabível em determinadas circunstâncias, a nova lei concedeu ainda ampla discricionariedade ao juiz para decidir sobre a necessidade da segregação cautelar do indivíduo acusado da prática de violência contra a mulher, valendo-se de relações domésticas e familiares.

Em outros contextos sociais, o debate sobre os mecanismos de combate à violência de gênero não é novo, já tendo sido experimentadas diferentes alternativas. Em meados dos anos 80 houve uma reorientação geral do trabalho policial no âmbito da "violência conjugal", especialmente no Canadá e nos Estados Unidos, mas também em outros países, sendo reconhecidas três possibilidades básicas de encaminhamento nesses casos: a mediação por terceiro - Justiça Restaurativa; a separação do casal - Justiça de Família; e a prisão do agressor - Justiça Penal.

Tipicamente experimentado nos EUA, a partir dos anos 80 , e analisado em detalhe nas suas múltiplas facetas e diferentes conseqüências, a pesquisa publicada em The Minneapolis Police Experiment (Sherman; Berk, apud Rifiotis, 2004) é referência obrigatória neste campo. Porém, as suas conclusões sobre o impacto na reincidência, que seria menor em casos de detenção do que de separação, foram relativizadas na revisão de várias experiências 
realizadas nesse país a partir do caso de Minneapolis, em posterior publicação de Lawrence W. Sherman (1992, apud Rifiotis, 2004).

Com base nos estudos realizados, concluiu-se que a detenção atua sempre de modo seletivo e temporário em termos de classe social e pertença étnica e cultural, e dificulta a busca de meios efetivos para prevenir a reprodução crônica da "violência conjugal", e que a detenção como mecanismo de combate à "violência conjugal" implica o abandono de outros meios e desconsidera o seu caráter sociocultural.

As lideranças do processo de elaboração da Lei n ${ }^{\circ}$ 11.340/06 desconsideraram estas conclusões. É o que se constata na manifestação de uma delas, Valéria Pandjiarjian, no site www.mulheresdeolho. org.br, que acaba por referendar o movimento pró-detenção:

Mas ainda precisamos, também, ao mesmo tempo, firmar a posição de que em muito casos a prisão em crimes de ameaça e lesão corporal leve é importante e necessária. Senão tanto e sempre como condenação, seguramente ao menos a prisão em flagrante e a preventiva são fundamentais para quiçá a maioria dos casos. Por menor tempo que seja, a prisão em flagrante ou a prisão preventiva do agressor pode ser até mesmo vital para a mulher em situação de violência, inclusive para dar tempo a essa mulher de resolver o caos da sua vida e de seus filhos sem a perseguição e o risco de morte por parte do agressor.

Eu sou pelo direito penal mínimo. Mas não sou contra a possibilidade de prisão do agressor, nos casos em que realmente é imprescindível. Há casos em que precisa de prisão sim, e precisamos deixar isso bem claro, inclusive para contrarrestar os argumentos de nossos amigos que se opõem e dizem que estamos indo pelas vias convencionais e ultrapassadas do direito penal.

O que se quer aqui destacar é que o processo de elaboração da Lei 11.340/06 não incorporou o debate mais recente sobre os mecanismos necessários para a elaboração, implantação e monitoramento dos novos procedimentos judiciais, na linha de uma 
Sociologia Jurídico-Penal, muito menos o legado da Criminologia Crítica no tocante aos problemas advindos da adesão à alternativa punitiva como solução de problemas sociais.

As medidas não-penais de proteção à mulher em situação de violência, previstas nos artigos $9^{\circ}, 22$ e 23 da Lei Maria da Penha, mostram-se providências muito mais sensatas para fazer cessar as agressões e, ao mesmo tempo, menos estigmatizantes para o agressor, assim como a ampliação da definição da violência contra as mulheres. Entretanto, inseridas em um contexto criminalizante, pode-se imaginar que logo estaremos assistindo à colonização das medidas protetivas pelas iniciativas tendentes à punição (mesmo antes da condenação) dos supostos agressores, nos casos que conseguirem ultrapassar a barreira do inquérito e alcançarem uma audiência judicial, quem sabe quanto tempo depois do momento da agressão. E ainda, como lembra Maria Stella de Amorim (2008, p. 15),

embora festejada por todos, inclusive pelos autores aqui citados e que não the pouparam observações, a operacionalização e a eficácia da Lei Maria da Penha pode sofrer da mesma fragilidade institucional que os JECrim. Se este despenalizava, a Lei Maria da Penha penaliza a violência contra a mulher. ${ }^{3}$ Se o JECrim falhou, por falta de políticas auxiliares no combate desta violência grave e ainda bastante arraigada nas sociedades atuais, inclusive na brasileira, a Lei 11.340/06 amparou-se em rede de proteção do Judiciário, do Ministério Público, da Defensoria Pública, dos Executivos Federais, Estaduais e Municipais, de equipes multidisciplinares e de organizações não-governamentais. Mas, estará esse extenso manto protetor suficientemente articulado para conceder proteção à mulher vítima da violência doméstica e familiar?

\section{Considerações finais}

O conflito de gênero que está por trás da violência doméstica não pode ser tratado pura e simplesmente como matéria criminal. 
O retorno do rito ordinário do processo criminal para apuração dos casos de violência doméstica não leva em consideração a relação íntima existente entre vítima e acusado, não sopesa a pretensão da vítima nem mesmo seus sentimentos e necessidades. Conforme a observação de Maria Filomena Gregori (1993), as mulheres atendidas não buscam, necessariamente, a separação de seus parceiros. A autora entende que não há uma simples dominação das mulheres pelos homens, estas não são meras vítimas de seus companheiros, não existe, numa relação, um estabelecimento dualista e fixo dos papéis de gênero. Embora a dualidade vítima-agressor facilite a denúncia da violência, Gregori (1993, p. 134), destaca que deve haver limites para essa visão jurídica dualista: a construção de dualidades - como 'macho' culpado e mulher 'vitima' - para facilitar a denúncia e indignação, deixando de lado o fato de que os relacionamentos conjugais são de parceria e que a violência pode ser também uma forma de comunicação, ainda que perversa, entre parceiros.

A leitura criminalizante apresenta uma série de obstáculos para a compreensão e intervenção nos conflitos interpessoais, não corresponde às expectativas das pessoas atendidas nas delegacias da mulher e tampouco ao serviço efetivamente realizado pelas policiais naquela instituição. Certamente o mais adequado seria lidar com esse tipo de conflito fora do sistema penal, radicalizando a aplicação dos mecanismos de mediação, realizada por pessoas devidamente treinadas e acompanhadas de profissionais do Direito, Psicologia e Assistência Social. Os Juizados Especiais Criminais abriram espaço para experiências bem-sucedidas neste âmbito, como as várias alternativas de encaminhamento do caso (compromisso de respeito mútuo, encaminhamento para grupo de conscientização de homens agressores, etc.) dão conta. No entanto, a falta de adesão normativa e institucional a mecanismos efetivos para a mediação dos conflitos e o equívoco da banalização da cesta básica deflagraram a reação que agora assistimos. 
Como se constata em matéria publicada pelo jornal Estado de São Paulo de 20 de maio de 2007, são no mínimo duvidosos os efeitos produzidos pelas mudanças legais introduzidas pela Lei 11.340/06. Conforme a matéria, fundamentada em dados fornecidos pelas delegacias da mulher de São Paulo, em seis meses de vigência da Lei n ${ }^{\circ} 11.340 / 06$, o número de denúncias caiu 18,8\%. A queda no número de denúncias foi registrada no período de outubro de 2006 a março de 2007, quando foram registrados 132.649 boletins de ocorrência. Entre outubro de 2005 e março de 2006, foram 163.441 .

A explicação pode ser buscada na manifestação do Promotor de Justiça Camilo Pileggi, da Comarca de Santana (SP), onde se verifica a resistência das vítimas para judicializar o conflito, mesmo no âmbito dos JECrim, pelo receio da possibilidade de prisão do agressor. Segundo ele,

Uma constante se presenciava nas audiências de instrução antes do advento da Lei no 9099/95: negativa de existência da agressão; negativa de autoria ou até a admissão de fato inverídico como a vítima lesionou-se porque bateu a cabeça na mesa, pois escorregara quando lavava a cozinha, dentre outras "histórias". Acabava o Magistrado absolvendo por falta de provas ou por "política criminal". Na Promotoria de Justiça Criminal de Santana demorou-se vários anos para convencer as mulheres que o oferecimento de representação não acarretaria a prisão do marido ou companheiro, mas somente com esta manifestação se poderia aplicar medidas restaurativas ou mediadoras. (Pileggi, 2007).

Como conclusão, pode-se afirmar que o aumento da demanda por mediação pública nos conflitos intrafamiliares e as críticas ao tratamento homogeneizador e criminalizante apontam em direção a novas formas de mediação, propiciadas de forma parcial pelos JECrim. Estes processos parecem revelar não uma volta à privatização do mundo doméstico, mas uma nova relação entre as instâncias do "público" e do "privado". Com a Lei no 11.340/06, 
ao invés de avançar e desenvolver mecanismos alternativos para a administração de conflitos, possivelmente mais eficazes para alcançar o objetivo de redução da violência, mais uma vez recorreuse ao mito da tutela penal, neste caso ela própria uma manifestação da mesma cultura que se pretende combater.

\title{
Notas
}

1 Sobre a utilização do discurso punitivo pelos defensores dos Direitos Humanos e as conseqüências deste fenômeno, vide o excelente trabalho de Helena Singer (1998).

2 Essas idéias já se encontram desenvolvidas na obra Legitimation durch Verfahren, editada pela primeira vez na Alemanha em 1969, e publicada no Brasil, em 1980 pela Ed. UnB (Legitimação pelo Procedimento).

3 Apesar do anteprojeto da lei admitir cinco anos de prisão para o agressor, a lei Maria da Penha, depois de aprovada, consigna de três meses a três anos de prisão para o agressor, ou seja, mais um ano da pena máxima admitida pelos Juizados Criminais, embora o Código Penal registrasse até um ano de pena para agressões leves para qualquer tipo de agressor. Porém, a Lei Maria da Penha altera o Código Penal ao introduzir pena de até $\operatorname{tr}^{\wedge} \mathrm{s}$ anos de reclusão para crimes de violência específica contra a mulher, inclusive para agressões leves, o que leva esses delitos a serem tratados como ações públicas incondicionadas à representação da vítima.

\section{Penal System and Gender-based violence: a sociojuridical analysis of the Law N. 11.340/06}

\begin{abstract}
The present article makes a reflection upon the role of the Sociology of Law on understanding the operation of the legislative activity, in order to analyze rationality and the probable effects of Law N. 11.340/06 (Maria da Penha Law). One concluded that, instead of moving forward and developing alternative mechanisms for the administration of conflicts, possibly more effective to
\end{abstract}


reduce violence, once more, one recurred to the myth of the penal protection, in this case, a manifestation of the same culture one intended to combat.

Keywords: juridical sociology, gender-based violence, Law N. $11.340 / 06$.

\section{Referências bibliográficas}

AMORIM, Maria Stella. Acesso à justiça e administração judicial da violência contra a mulher brasileira: políticas de despenalização e de penalização. Anais do XIII Congresso da Anpedi. Disponível em: $<$ http://conpedi.org/manaus////arquivos/anais/campos/maria_stella_ de_amorim.pdf $>$.

BARATTA, Alessandro. Criminologia crítica e crítica do Direito Penal. 2. ed. Rio de Janeiro: Freitas Bastos, 1999.

BECKER, Howard. Outsiders: studies in the Sociology of Deviance. New York: Free Press, 1991.

DAHRENDORF, Ralf. Ley y orden. Madri: Ed. Civitas, 1994.

DIAS, Maria Berenice. A Lei Maria da Penha na Justiça. São Paulo: Revista dos Tribunais, 2007.

DOMÍNGUEZ FIGUEIRIDO, José Luis. Sociologia jurídico-penal y actividad legislativa. In: BERGALLI (Coord.). Sistema penal y problemas sociales. Valencia: Tirant lo Blanch, 2003.

ESTADO DE SÃO PAULO (O).Versão online. 28 maio 2007.

GREGORI, Maria Filomena. Cenas e queixas: um estudo sobre mulheres, relações violentas e a prática feminista. São Paulo: Paz e Terra, 1992.

LARRAURI, Elena. La herencia de la criminología crítica. Madri: Siglo Veintiuno, 1991. 
LEA, John; YOUNG, Jock. Qué hacer con la ley y el orden? Buenos Aires: Ed. Del Puerto, 2001.

LUHMANN, Niklas. Legitimação pelo procedimento. Brasília, EdUnB, 1980.

LUHMANN, Niklas. A posição dos tribunais no sistema jurídico. Ajuris, Porto Alegre, v. 17, n. 49, p. 149 - 168, jul. 1990.

PANDJIARJIAN, Valéria. Blog Visão crítica sobre a Lei Maria da Penha. Disponível em: $<w w w . m u l h e r e s d e o l h o . o r g . b r>$. Acesso em: 20 jun. 2007.

PASINATO, Wania. Delegacias de Defesa da Mulher e Juizados Especiais Criminais: mulheres, violência e acesso à justiça. In: ENCONTRO DA ASSOCIAÇÃO NACIONAL DE PÓS GRADUAÇÃO EM CIÊNCIAS SOCIAIS (ANPOCS). 28. Caxambu, Minas Gerais, 2004. CD-ROM.

PILEGGI, Camilo. Lei Maria da Penha: acertos e erros. Disponível em: <www.mp.sp.gov.br/pls/portal/docs/page/cao_civel/palestra.doc>. Acesso em: 20 jun. 2007.

RIFIOTIS, Theophilos. As delegacias especiais de proteção à mulher no Brasil e a "judiciarização" dos conflitos conjugais. Sociedade e Estado, v. 19, n. 1, p. 85-119, jan/jul 2004.

SILVA SÁNCHEZ, Jesús-María. A expansão do Direito Penal: aspectos da politica criminal nas sociedades pós-industriais. Trad. Luiz Otávio de Oliveira Rocha. São Paulo: Ed. Revista dos Tribunais, 2002.

SINGER, Helena. Direitos humanos e volúpia punitiva: o caso do Brasil. Coimbra: Centro de Estudos Sociais, 1998. (Oficinas do CES $\mathrm{n}^{\mathrm{o}}$ 117).

SOARES, Bárbara Musumeci. Mulheres invisiveis: violência conjugal e as novas políticas de segurança. Rio de Janeiro: Civilização Brasileira, 1999.

TREVES, Renato. La Sociología del Derecho: origenes, investigaciones, problemas. Barcelona: Ariel, 1988. 